\title{
Sławomir Wacewicz \\ The narrow faculty of language: What is it, who has it, and how is it defined?*
}

\section{Introduction}

Commentators on the research into the evolution of language frequently note the unprecedented increase in the number of publications on this topic in the last decade of the twentieth century (see e.g. Christiansen \& Kirby 2003a). Many also point out that the change was not only quantitative. The very nature of this interest was becoming different from earlier speculations about the origins of language, with new computational tools and bodies of empirical evidence finally substantiating the claims of academic rigour (e.g. Christiansen \& Kirby 2003b). But this upsurge also produced some degree of conceptual confusion: it became evident that researchers with different disciplinary backgrounds understood the evolution of language in vastly different ways. What exactly was it that evolution of language research should aim to explain? There emerged a need for a more precise self determination of this research field and defining its explanatory goals, which involved a disambiguation of the very term evolution of language.

The concept of evolution presented itself as relatively unproblematic. A very broad, non-technical construal along the lines of "the phylogenetic emergence of a biological trait in a species" was sufficiently inclusive and innocuous to be implicitly accepted as universal common ground. If real - not purely verbal - debates could continue over the particular selection pressures, preconditions, developmental trajectories, stages (e.g. Jackendoff 1999), modalities (e.g. Corballis 2002), rates of change (e.g. Worden 1995), the

* This research was supported by grant 3704/B/H03/2011/40 from the Polish National Science Centre. 
relative importance of particular mechanisms such as natural selection (e.g. Pinker \& Bloom 1990), or even the overall scientific value of explanations offered (Lewontin 1998) - it was precisely because the general notion of evolution that was present in the background was not problematic.

Language, on the other hand, had always been a refractory notion. Two obvious complicating factors were its multilayered ontology, and the plurality of historical and contemporary approaches coexisting within linguistics and philosophy. In the specific context of the evolution of language, however, the principal difficulty seemed to arise from the interdisciplinary nature of this research field. Not a proprietary notion of any single discipline, "language" had come to be used differently in each of the involved branches of knowledge, reflecting their respective theoretical interests and biases, and this in turn leading to hidden assumptions. As one example, Rudolph Botha (2000) enumerates thirteen different designations of the term "language" contained in a single edited volume.

In an attempt to remedy this situation, ${ }^{1}$ three influential scholars in disciplines relevant to the evolution of language - the comparative psychologist Marc Hauser, the linguist Noam Chomsky and the biologist Tecumseh Fitch - wrote a paper designed to lay down a general conceptual framework within which a (more) meaningful discussion about the evolution of language could take place (Hauser et al. 2002). Specifically, they made a consequential terminological/conceptual distinction, dividing the faculty of language into FLN (Faculty of language - narrow sense) and FLB (Faculty of language - broad sense). Unfortunately, three years later, debating Pinker and Jackendoff, the three authors dropped their original definition of this distinction and replaced it with another (Fitch et al. 2005). Far from achieving their goal "to clarify misunderstandings and aid interdisciplinary rapprochement" (Fitch et al. 2005: 179), establishing two conflicting definitions of FLN/FLB had the effect of further adding to the confusion.

In the rest of this paper I argue that:

a) the concept of FLN/FLB has acquired central importance in the evolution of language and has also achieved recognisable status beyond that field;

b) the two definitions of the FLN/FLB concept do not just differ insignificantly, but rather they differ fundamentally in a way that precludes their reconciliation;

1 In a later text, Fitch (2010: 22) makes his motivation clear: "We coined this term [FLN] simply to clarify discussion and avoid confusion, once we realized that researchers (including ourselves) had been using the same word, 'language,' to talk about two different things (FLB and FLN) for many years, and thus had been talking past each other". 
c) because of the centrality of the FLN/FLB concept, the conflict between the two definitions is not a trivial terminological matter but has important consequences for the research field of the evolution of language.

Although thematically related, this text is not intended as an investigation of the theoretical position of Hauser, Fitch and Chomsky or as a comprehensive summary of their debate with Pinker and Jackendoff. These topics have already received very extensive coverage in existing analyses from a number of authors including myself (see Wróbel, this issue; Barceló-Coblijn, this issue - Wacewicz 2007, Lewandowska-Tomaszczyk 2008). Rather, as stated above, it specifically targets an isolated but arguably crucial terminological distinction between FLN and FLB.

\section{FLN 1: the 2002 definition}

In the original 2002 paper by Hauser, Chomsky and Fitch, the authors put forward a number of interesting strong hypotheses that have canalised a sizeable proportion of the subsequent research into the evolution of language (especially the "recursion only" hypothesis - see e.g. Parker 2006). Nevertheless, the centrepiece of their paper was none of the empirical hypotheses, but rather the terminological distinction into FLN and FLB.

Hauser et al. (2002) unambiguously define FLN as the "computational core" of the language faculty: the cognitive subsystem responsible for generating the discrete infinity of linguistic expressions. Importantly, FLN thus defined is a term internal to linguistic theory, as the criteria for its delineation are not interdisciplinary, but rather remain entirely within the domain of linguistics. In other words, the distinction into FLN and FLB is one made by the linguist and based on a particular theoretical account of language (and thus of "the language faculty"), without resort to data or expertise from other disciplines such as comparative biology or psychology.

As originally defined, FLN, the core device for abstract grammatical operations, is one part of the more general faculty of language in the broad sense (FLB), which also includes at least two other major components: the sensorimotor (SM) subsystem and the conceptual-intentional (CI) subsystem. SM and CI are not explained in detail. Hauser et al. (2002) illustrate them by examples and make it clear that those subsystems do not process "linguistic" representations, but rather interface with the FLN via phonology and formal semantics, respectively. 
The relation between FLN and FLB, as presented in Hauser et al. 2002, is captured in Figure 1 below.

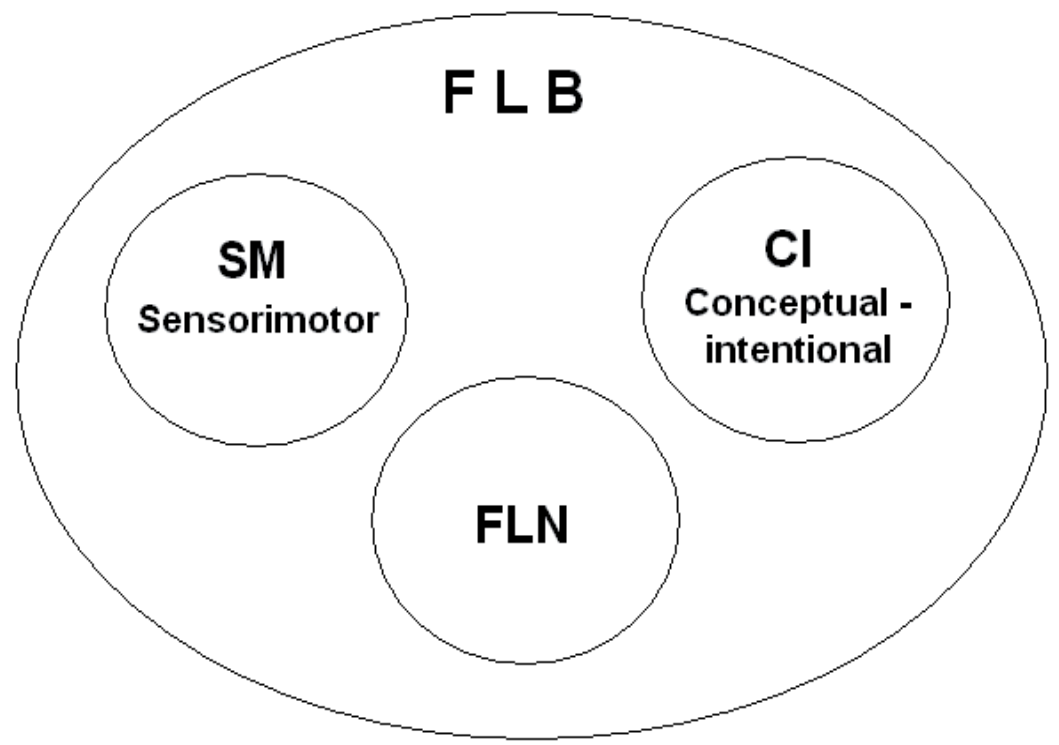

Fig 1. The FLN/FLB distinction in Hauser et al. 2002

In the entire paper, a single passage can be found that does hint - albeit unclearly - at the possibility of a construal of the FLN/FLB distinction alternative to one just described:

For example, Liberman and his associates... have argued that the sensory-motor systems were specifically adapted for language, and hence should be considered part of FLN... In this article, we leave these questions open, restricting attention to FLN as just defined but leaving the possibility of a more inclusive definition open to further empirical research. (2002: 1571)

The above fragment could be read as suggesting that distinguishing FLN from SM or CI is a matter of hypothesis, not definition. However, this interpretation does not find any support elsewhere in the text:

Faculty of language-broad sense (FLB). FLB includes an internal computational system (FLN, below) combined with at least two other organism-internal systems, which we call <sensory-motor> 
and <conceptual-intentional.> (2002: 1569-1570) [italics in the original]

FLB includes sensory-motor, conceptual-intentional, and other possible systems (which we leave open); FLN includes the core grammatical computations that we suggest are limited to recursion. (2002: 1570; caption for Fig. 2 in that paper)

Faculty of language-narrow sense (FLN). FLN is the abstract linguistic computational system alone, independent of the other systems with which it interacts and interfaces. (2002: 1571) [italics in the original]

This research space identifies, as viable, problems concerning the evolution of sensory-motor systems, of conceptual-intentional systems, and of FLN. (2002: 1571)

By this hypothesis, FLB contains a wide variety of cognitive and perceptual mechanisms shared with other species, but only those mechanisms underlying FLN - particularly its capacity for discrete infinity - are uniquely human. (2002: 1573) [italics for emphasis - SW]

Second, although we have argued that most if not all of FLB is shared with other species, whereas FLN may be unique to humans, this represents a tentative, testable hypothesis in need of further empirical investigation. (2002: 1576) [italics for emphasis - SW]

Hypothesis 3: Only FLN is uniquely human. (2002: 1573) [italics in the original]

The last three quotes are unequivocal and conclusive. Quite obviously, a hypothesis regarding the nature of some unobserved, postulated entity is something necessarily different from a definition of that entity: the former is a statement awaiting corroboration or falsification by empirical data not yet present or accessible, whereas the latter is a stipulation indifferent to any further empirical findings. The relation between the two is mutually exclusive, i.e. one and the same statement cannot simultaneously function as a definition of a phenomenon and an empirical hypothesis about it. In Hauser et al. (2002), the "uniqueness to humans" feature of FLN is tagged, repeatedly and explicitly, as a hypothesis about FLN, which decisively bars the possibility of this feature being part of FLN's definition. 


\subsection{Summing up - FLN in Hauser et al. (2002)}

\section{Definitions:}

FLN is the core computational mechanism of the broadly defined language faculty.

Hypotheses:

FLN is the part of FLB that is unique to humans (i.e. FLN is unique to humans, and no other part of FLB is).

FLN can be equated with recursion.

\section{FLN 2: the 2005 definition}

As stated above, the 2005 article by Fitch, Hauser and Chomsky (published as a reply to Pinker \& Jackendoff 2005) provides a different definition of the FLN/FLB distinction. FLN is no longer listed as a specific component of FLB alongside SM and CI. Instead, FLB as now described includes SM, CI and "the computational components of language that have been the traditional focus of study in modern linguistics," and the whole division is played down as only "one potential cut through FLB" (Fitch et al. 2005: 182). Fitch et al. (2005) now claim that FLN is defined through being unique to both humans and language.

To this end, we denoted "language" in a broad sense, including all of the many mechanisms involved in speech and language, regardless of their overlap with other cognitive domains or with other species, as the "faculty of language in the broad sense" or FLB. This term is meant to be inclusive, describing all of the capacities that support language independently of whether they are specific to language and uniquely human. Second, given that language as a whole is unique to our species, it seems likely that some subset of the mechanisms of FLB is both unique to humans, and to language itself. We dubbed this subset of mechanisms the faculty of language in the narrow sense (FLN). (Fitch et al. 2005: 180-181)

We thus made the further, and independent, terminological proposal to denote that subset of FLB that is both specific to language and to humans as FLN. To repeat a central point in our paper: FLN is composed of those components of the overall faculty of language (FLB) that are both unique to humans and unique to or clearly specialized for language. (Fitch et al. 2005: 182) 
The relation between FLN and FLB, as redefined in Fitch et al. 2005, is captured in Figure 2 below.

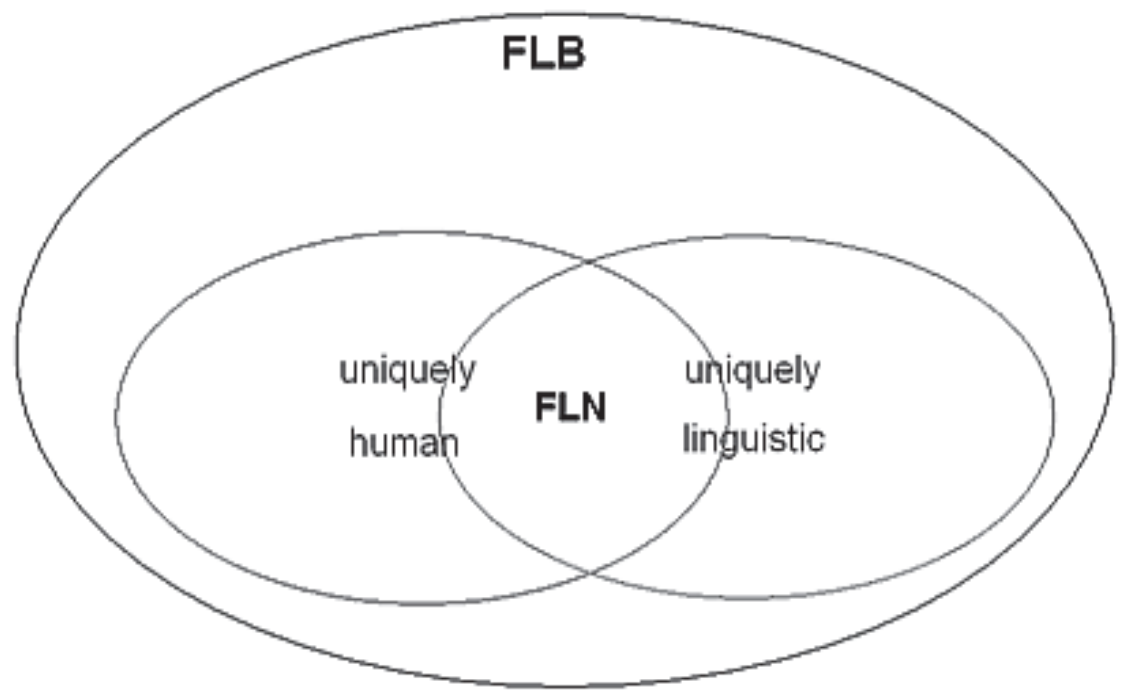

Figure 2. The FLN/FLB distinction in Hauser et al. 2002

Not surprisingly, the reversal of the content of their terminological proposal and empirical hypothesis relative to the 2002 text by those authors results in direct contradictions. Compare:

The contents of FLN are to be empirically determined, and could possibly be empty, if empirical findings showed that none of the mechanisms involved are uniquely human or unique to language, and that only the way they are integrated is specific to human language. The distinction itself is intended as a terminological aid to interdisciplinary discussion and rapprochement, and obviously does not constitute a testable hypothesis. (Fitch et al. 2005: 180181)

Second, although we have argued that most if not all of FLB is shared with other species, whereas FLN may be unique to humans, this represents a tentative, testable hypothesis in need of further empirical investigation. (Hauser et al. 2002: 1576) 


\subsection{Summing up - FLN in Fitch et al. (2005)}

Definitions:

FLN is the part of FLB that is unique to humans.

Hypotheses:

Only recursion is unique to humans.

\section{The possible counterarguments}

In what follows, I establish my claims listed in Section 1 by outlining the possible counterarguments against them ${ }^{2}$ and then addressing each of those in turn.

\section{1. "The FLN/FLB distinction was corrected in the 2005 text"}

While in their second text the authors are indeed explicit about the criteria of the FLN/FLB distinction, two rather grave problems remain.

Firstly, the discrepancy between the 2002 paper and the 2005 followup has never been acknowledged. In Fitch et al. (2005: 181-183), through a series of demonstrably false claims, the authors maintain that the "FLN2" definition, and hence the "uniqueness to humans" criterion, was in place in the original paper. The authors' failure to acknowledge the contradiction and their misreporting their own text are a source of confusion and reason for concern.

The above point might be a trivial one if it was the latter text by the three authors that had the status of a classic. However, since the FLN/ FLB distinction was introduced in 2002, it is the original Science paper that functions as the classic reference in research and education related to language evolution and related disciplines (see 4.2 below). As one example, it has repeatedly been claimed that Hauser et al. (2002) define FLN as those aspects of the language faculty that are unique both to humans and to language (e.g. Samuels 2009: 356) - which, as has been shown here, is simply not true. Ascribing to sources content that is not present there is hardly conducive to good scholarship.

Secondly, and more importantly, Fitch, Hauser and Chomsky themselves continue to use the FLN/FLB terminology in two disparate senses without

2 Some of those counterarguments are based on discussions during and after the conferences Evolang 6, Evolang 7 and Protolang 1. 
any acknowledgement of this problem, therefore propagating confusion. Fitch (e.g. 2005, 2010) appears to be dedicated to, and consistent in, the later interpretation, FLN2, i.e. with the "double uniqueness" criterion. In contrast, Chomsky's (e.g. 2007) main commitment seems to be the delineation of the core linguistic component of the faculty of language as distinct from the SM and CI systems, which would strongly suggest his embracing FLN1. Hauser, however, at different occasions subscribed to both the "computational core" (FLN1) and "double uniqueness" (FLN2). Compare:

FLN - and especially the mechanism of recursion - was defined by Hauser et al. (2002) as a computational process that is responsible for the generative and hierarchical properties of narrow syntax." (Tincoff \& Hauser 2006: 536)

FLB is simply those processes of the mind that are both necessary and sufficient to support language. Thus, for example, attention is involved in language processing but is neither unique to language nor unique to humans. FLN includes those processes that are both uniquely human and unique to language. Providing a demonstration that a particular process is uniquely human doesn't clinch its place in FLN, as it is possible that this uniquely human process is implemented in other domains of human knowledge, and thus, not unique to language. (Hauser et al. 2007: 105)

As a result, FLN lives on in the two distinct, discrepant senses both of which are widely represented in current literature on the evolution of language: see e.g. Armstrong and Wilcox (2007), Johansson (2005), Kurcz (2004), Lewandowska-Tomaszczyk (2008) - FLN1; and Okanoya (2007), Parker (2006), Samuels (2009), and Számadó and Szathmáry (2006) - FLN2. Occasionally (e.g. Kinsella 2009), authors equivocate between the two interpretations, conflate them or use interchangeably without recognizing the qualitative difference.

\section{2. "The FLN/FLB distinction is not central but only peripheral to the evolution of language research"}

The FLN/FLB distinction is arguably the single most important concepts in language evolution, and the topic of FLN/FLB remains in the centre of conferences and edited volumes in this research field. Of course, "importance" is difficult to measure objectively, but several factors serve as strong indicators of such a status. Firstly, the FLN/FLB is one of the very 
few terminological-conceptual exports from the field of language evolution to the study of language at large. This is confirmed by the presence of this distinction in respectable tertiary literature such as The Stanford Encyclopedia of Philosophy or The Encyclopedia of Language and Linguistics.

Secondly, the text by Hauser et al. (2002), consisting almost exclusively in formulating and expounding the FLN/FLB concept, has effectively become not only one of the most influential papers in the evolution of language research but probably the most influential one. In this case, importance is measurable more directly by the number of citations; Hauser et al. (2002) is reported as cited 608 times by the ISI Web of Knowledge, 1730 times by Google Scholar. In comparison, the figures for Pinker and Bloom (1990), widely recognised as the flagship of the field of language evolution (e.g. Christiansen \& Kirby 2003a), are 414 citations in the ISI Web of Knowledge and 1427 in Google Scholar ${ }^{3}$ - despite its being published more than a decade earlier. For additional arguments regarding the significance of this former text see Wróbel (this issue).

\section{3. "The difference between FLN1 and FLN2 is insubstantial and has no tangible effect on research into the evolution of language"}

The difference between FLN1 and FLN2 is neither purely verbal nor trivial, which is best attested to by the inferences generated by each of those interpretations. Two questions can be considered as examples, one of a more conceptual nature, and the other with very real consequences in framing research priorities.

Question 1: Can FLN be an empty set?

FLN1 automatically precludes this possibility. On definition 2, however, such a possibility exists, and is asserted repeatedly, in Fitch et al. (2005).

Question 2: Could analogous traits be part of FLN?

Definition 1 allows such a possibility, but given FLN 2, this is ruled out. Assuming that at least one of the original goals behind the FLN/FLB distinction was to avoid the conflation of all the research questions to the domain of FLB - in other words, to single out FLN as a special, "nobler" explanatory target - it is not at all clear what theoretical gains would follow from FLN2. One disturbing consequence would be that a trait crucial to language use in contemporary humans (e.g. vocal imitation) would somehow become "less interesting" once an analogue of it is found

3 All searches on 14.02.2011. Parameters for ISI Web of Knowledge: Timespan=All Years. Databases=SCI-EXPANDED, SSCI, A\&HCI, CPCI-S, CPCI-SSH. 
in another species. Additional problems arise with deciding about the identity of particular traits, i.e. how to judge whether an analogous trait counts as the same trait - but such problems have already been covered by previous commentators.

Finally, FLN2 is hardly an improvement over FLN1, as it offers no definition of language that this field of research could use. When dealing with the evolution of language, the question of "what counts as language" is one that is ultimately impossible to escape. Indeed, providing a workable definition of language for language evolution studies seems to have been the original motivation of Hauser et al. (2002), and FLN1 gave a coherent and acceptable (if controversial) answer. In contrast, FLN2, based on the "double uniqueness" criterion, is at a different level and itself presupposes some answer to this more fundamental question of how to delineate "language."

\section{Conclusion}

The evolution of language, as a research area, is special in many ways. One of those ways is its inherently interdisciplinary status with its usual afflictions, i.e. the terminological barriers to fruitful communication of researchers with different backgrounds. The FLN/FLB concept, created with intent to improve this condition, has now become an influential but fundamentally confused bit of terminology, complicating rather than clarifying dialogue across disciplinary borders.

The suggested overall conclusions are twofold. Firstly, researchers into language evolution should not accept the FLN/FLB distinction at face value, but rather refer meticulously to primary literature. Ultimately, it is hoped that the FLN/FLB distinction will be supplanted by a more compelling one, driven by a more coherent research agenda. Until then, FLN1, i.e. FLN as defined in Hauser et al. (2002), should probably be used, both for reasons of priority and theoretical usefulness.

As a second point, it is astonishing that such a major conceptual inconsistency between the two definitions of FLN/FLB has remained essentially unnoticed or ignored. This may be due to the proclaimed "clarification" of this issue in Fitch et al. (2005); however, as has been demonstrated, this "clarification," based on demonstrably false claims, only added to the confusion. It may signal a need for a radical top-down examination and discussion of the terminological-conceptual inventory of the evolution of language before this field develops its own tertiary literature. 


\section{References}

Armstrong, D. \& Wilcox, S. (2007). The Gestural Origin of Language. Oxford: Oxford University Press.

Barceló-Coblijn, L. (This volume). Evolutionary Scenarios for the Emergence Of Recursion.

Botha, R. (2000). Discussing the evolution of the assorted beasts called language. Language \& Communication 20, 149-160.

Christiansen, M. \& Kirby, S. (2003a). Language Evolution: the Hardest Problem in Science? In M. Christiansen \& S. Kirby (Eds.), Language Evolution (pp. 1-15). Oxford: Oxford University Press.

Christiansen, M. \& Kirby, S. (2003b). Language evolution: consensus and controversies. Trends in Cognitive Sciences 7(7), 300-307.

Chomsky, N. (2007). Biolinguistic Explorations: Design, Development, Evolution. International Journal of Philosophical Studies 15, 1-21.

Corballis, M. (2002). From Hand to Mouth: The Origins of Language. Princeton, NJ: Princeton University Press.

Fitch, T. (2005). The evolution of language: a comparative review. Biology and Philosophy 20, 193-230.

Fitch, T. (2010). The evolution of language. Cambridge: Cambridge University Press.

Fitch, T., Hauser, M. \& Chomsky, N. (2005). The evolution of the language faculty: clarifications and implications. Cognition. 97(2), 179-210.

Hauser, M., Chomsky, N. \& Fitch T. (2002). The Faculty of Language: What. Is It, Who Has It, and How Did It Evolve? Science 298, 1569-1579.

Hauser, M., Barner, D. \& O’Donnell, T. (2007). Evolutionary linguistics: a new look at an old landscape. Language Learning, and Development, 3(2), 101-132.

Jackendoff, R. (1999). Possible stages in the evolution of the language capacity. Trends in Cognitive Sciences, 3(7), 272-279.

Johansson, S. (2005). Origins of Language: Constraints on hypotheses. Amsterdam: John Benjamins.

Kinsella, A. (2009). Language Evolution and Syntactic Theory. Cambridge: Cambridge University Press.

Kurcz, I. (2004). Communicative Competence and Theory of Mind. Psychology of Language and Communication 8(2), 5-18.

Lewandowska-Tomaszczyk, B. (2008). Czym jest język? Dzisiejsze kontrowersje $\mathrm{w}$ paradygmatach generatywnych i kognitywnych. In P. Stalmaszczyk (Ed.), Metodologie językoznawstwa: współczesne tendencje i kontrowersje (pp. 9-26). Kraków: Lexis.

Lewontin, R. (1998). The evolution of cognition: Questions We Will Never Answer. In D. Scarborough \& S. Sternberg (Eds.), An invitation to cognitive science, Volume 4: Methods, models, and conceptual issues (pp. 107-132). Cambridge: MIT Press. 
Okanoya, K. (2007). Language evolution and an emergent property. Current Opinion in Neurobiology 17, 271-276.

Parker, A. (2006). Evolving the Narrow Language Faculty: Was Recursion the Pivotal Step? In A. Cangelosi, A. D. M. Smith \& K. Smith (Eds.), The Evolution of Language (pp. 239-246). Singapore: World Scientific Publishing.

Pinker, S. \& Bloom, P. (1990). Natural language and natural selection. Behavioral and Brain Sciences, 13, 707-784.

Pinker, S. \& Jackendoff, R. (2005). The Faculty of language: What's special about it? Cognition 95 (2), 201-236.

Samuels, B. (2009). The Third Factor in Phonology. Biolinguistics, 3 (2-3), 355382.

Számadó, S. \& Szathmáry, E. (2006). Selective scenarios for the emergence of natural language. Trends in Ecology \& Evolution, 21(10), 555-561.

Tincoff, R. \& Hauser, M. (2006). "Cognitive Basis for Language Evolution in Nonhuman Primates". In K. Brown (Ed.), Encyclopaedia of Language and Linguistics, 2nd edition (pp. 533-538). Amsterdam: Elsevier.

Wacewicz, S. (2007). Debata Hauser, Chomsky, Fitch - Pinker i Jackendoff. Nowoczesny spór o pochodzenie ludzkiej zdolności językowej. In Wróbel, S. (Ed.), Modularność umystu (pp. 79-94). Kalisz: WPA UAM.

Worden, R. (1995). A Speed Limit For Evolution. Journal of Theoretical Biology $176,137-152$.

Wróbel, S. (This volume). Rethinking Language Faculty. Has Language Evolved For Other Than Language Related Reasons. 